\title{
Short-Term Mineralization of Dentin and Enamel in the Mouse Embryonic Molars Cultured in Serum-Free, Chemically-Defined Medium
}

\author{
Naoki Fujiwara, Yasunori SaKaKura and Tokio Nawa \\ Department of Oral Anatomy, Iwate Medical University School of Dentistry, Morioka, Japan \\ Received April 28, 1990; revised manuscript received May 27, 1991
}

\begin{abstract}
Summary. The present study was designed to demonstrate the short term mineralization of dentin and enamel, and to investigate the effects of sodium $\beta$ glycerophosphate $\left(\mathrm{Na}-\beta-\mathrm{GPO}_{4}\right)$ on calcification in a serum-free, chemically-defined medium. The first mandibular molars at the bell stage dissected from 18-dayold mouse embryos were used as explants, which were cultured by an improved flotation method. Calcification of enamel in the 18-day-old embryonic molars occurred within the 6th day of culture. In another experiment, the molar germs were cultured in a serum-free, chemically-defined medium supplemented with 1,5 and $10 \mathrm{mM}$ $\mathrm{Na}-\beta-\mathrm{GPO}_{4}$. Promotion of tooth mineralization was recognizable at very low concentrations, such as $1 \mathrm{mM}$ $\mathrm{Na}-\beta-\mathrm{GPO}_{4}$, in 18-day-old embryonic tooth germs.

The culturing system reported here shortens the time required for dentin and enamel calcification to one half or one third of that reported previously and therefore should prove useful for examining regulations for cytodifferentiation and morphogenesis in tooth germs and the mineralization of dentin and enamel.
\end{abstract}

Previous reports have shown that dentin and enamel can be formed and mineralized in vitro in a pattern comparable to that in vivo. Earlier investigators have described how dentin and enamel biomineralization occurs in organ culture systems using chemically-defined media supplemented with serum or exogenous growth factors (HEY, 1961; WIGGLESWORTH, 1968; WIGGLESWORTH and HAYWARD, 1973; LEVENSON, 1976; THESLEFF, 1976; BRONCKERS et al., 1981, 1983; LAINE and THESLEFF, 1986; SAKAKURA, 1986; WOLTGENS et al., 1987). These results indicated that dentin and enamel biomineralization required serum-associated factors (SLAVKIN, 1979; YAMADA et al., 1980; BRONCKERS, 1983a, b; AMELOOT et al., 1986; LAINE and TheslefF, 1986; SAKAKURA, 1986). BRINGAS et al. (1987) and EvANS et al. (1988) reported that a chemi- cally-defined medium (BGJb medium, Fitton-Jackson modification) without serum caused calcification of dentin and enamel for up to three weeks. These serumless media have made it possible to identify unknown factors affecting the cytodifferentiation and biomineralization of embryonic teeth.

Recently, SLAVKIN and collaborators have been engaged in elucidating the factors and mechanisms of gene expression in relation to mouse embryonic tooth developments with the use of a long term culture (BRINGAS et al., 1987; EvANS et al., 1988) using slower growing embryonic molars as compared to in vivo (SLAVKIN et al., 1988, 1989, 1990). However, molars in situ do not require a long period of time for the mineralization of dentin and enamel. In fact, the shorter the culture period, the better one can observe the mineralization of dentin and enamel, and the more one can inquire about how closely related the in vitro conditions are to those of the in vivo state.

Generally, tooth germs cultured by modified Trowell methods result in defective three-dimensional structures of the molars, this being considered an important factor for its normal expression. However, the flotation method described by SAKAKURA (1986) and SAKAKURA et al. (1989) was able to maintain the three-dimensional structure during embryonic molar development.

Although many investigators have reported on bone and/or tooth germs mineralized under conditions supplemented with 5 or $10 \mathrm{mM}$ sodium $\beta$ glycerophosphate $\left(\mathrm{Na}-\beta-\mathrm{GPO}_{4}\right)$ and various sera (Tenenbaum and HeErsche, 1982; Bellows et al., 1986; LAINE and THESLEFF, 1986; GERSTENFELD et al., $1987)$, hardly any papers have reported the effects of $\mathrm{Na}-\beta-\mathrm{GPO}_{4}$ on tooth mineralization in a serum-free culture medium. The flotation method allowed us to observe the effects of various $\mathrm{Na}-\beta-\mathrm{GPO}_{4}$ concentra- 
tions on the calcification and development of tooth germs in a serum-free, chemically-defined medium.

In conclusion, the flotation method with the use of a serum-free, chemically-defined medium was found to be the most effective approach in observing the normal three-dimensional structure of the molar during its embryonic developmental stages. Furthermore, with the supplement of $\mathrm{Na}-\beta-\mathrm{GPO}_{4}$, this method proved to be a desirable culture system for studying tooth coronal mineralization.

\section{MATERIALS AND METHODS}

\section{Organ}

The mandibular first molars were aseptically dissected from 18-day-old ddY mouse embryos under a dissecting microscope. These isolated tooth germs were routinely stored in a control medium at $4^{\circ} \mathrm{C}$ until explanted in vitro. The first molars from the 18-dayold mice represented the bell stage of tooth morphogenesis, and the inner enamel epithelium remained undifferentiated (Fig. 1).

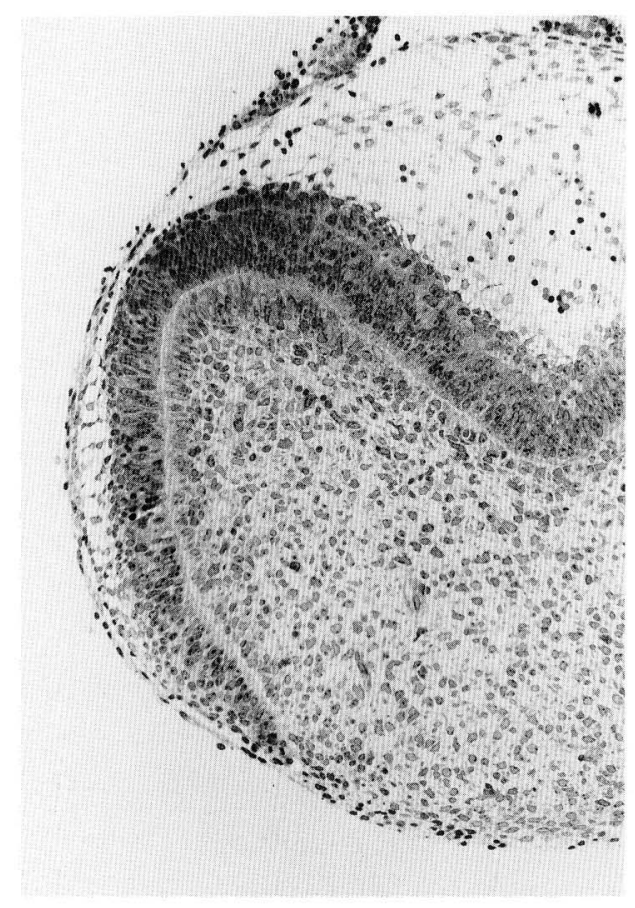

Fig. 1. An intact first mandibular molar of an 18-day-old mouse embryo at the bell stage of development. The cusp pattern has already formed and odontoblasts have begun to differentiate, while ameloblasts have not yet polarized. $\times 130$

\section{Culture medium}

A serum-free, chemically-defined medium which consisted of Dulbecco's modified Eagle medium (Nissui Pharmaceutical Co., LTD, Tokyo, Japan) supplemented with $0.584 \mathrm{~g} / 1 \mathrm{~L}$-glutamine, $40 \mathrm{mg} / 1 \mathrm{~L}$-proline, $150 \mathrm{mg} / 1$ ascorbic acid and $60 \mathrm{mg} / 1 \mathrm{kanamycin}$ was used. A total of four culture media were used, including the above culture medium alone, and three other culture media with the addition of 1,5 and $10 \mathrm{mM}$ sodium $\beta$-glycerophosphate to the above medium.

\section{Culture procedures}

The flotation method (SAKAKURA, 1986; SAKAKURA et al., 1989) consists of using a 24-well multidish (Nunc, Roskilde, Denmark), and a culture chamber (MillicellHA, Millipore Products Division., Bedford, Massachusetts, USA). The inner bottom of the culture chamber was coated with 1\% agar (Agar Noble, Difco Laboratories, Detroit, Michigan, USA) to prevent adhesion between the tooth germ and the filter. The explant was first placed on this filter, and the space between the chamber and the well of the multidish was filled with the medium described above. The medium gradually flowed into the culture chamber through the filter. Afterwards, the tooth germ slowly floated up until the medium reached the equilibrium level of both the inside and outside culture chamber. The explant was kept at the level of the gas-medium interface by the surface tension of the medium. All the cultured molars were then incubated at $37^{\circ} \mathrm{C}$ in a gas mixture of $5 \% \mathrm{CO}_{2}, 50 \% \mathrm{O}_{2}$ and $45 \% \mathrm{~N}_{2}$ saturated with water vapor, and cultured for $2,4,6,8$ and 10 days. The initial $\mathrm{pH}$ value of the medium was adjusted to 7.4 , and the medium was changed every other day.

\section{Histologic procedures}

At the end of the culturing periods, the molars were fixed in $2.5 \%$ glutaraldehyde in $0.05 \mathrm{M}$ cacodylate buffer ( $\mathrm{pH} 7.4$ ) for $1 \mathrm{~h}$ at $4^{\circ} \mathrm{C}$ and then postfixed in $1 \%$ osmium tetroxide in the same buffer for $1 \mathrm{~h}$ at $4^{\circ} \mathrm{C}$. After fixation, the explants were dehydrated in graded concentrations of ethanol and embedded in Epon 812.

For light microscopic observations, the molars were buccolingually sectioned and $2 \mu \mathrm{m}$-thick sections were stained with $0.1 \%$ toluidine blue. Ultrathin sections for transmission electron microscopy were stained with uranyl acetate and lead citrate.

\section{VON KOSSA assay}

The explants were cut into $2 \mu \mathrm{m}$-thick sections. Some sections were stained with toluidine blue 

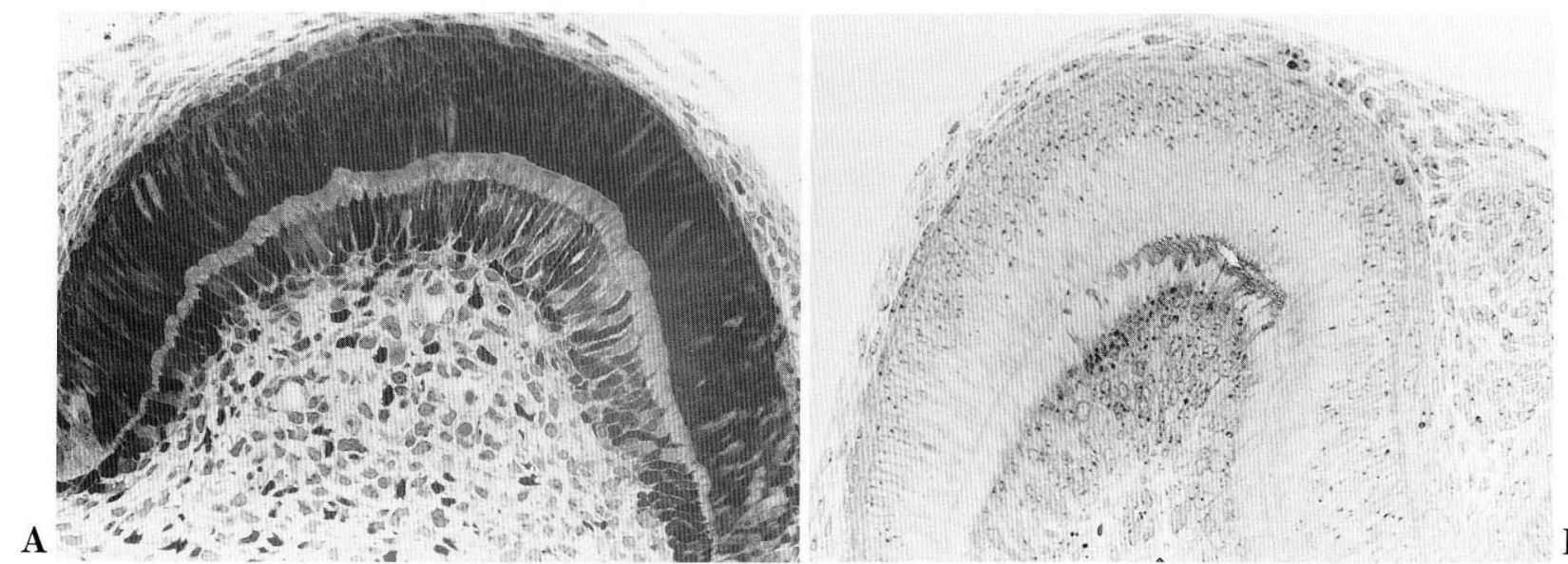

B

C
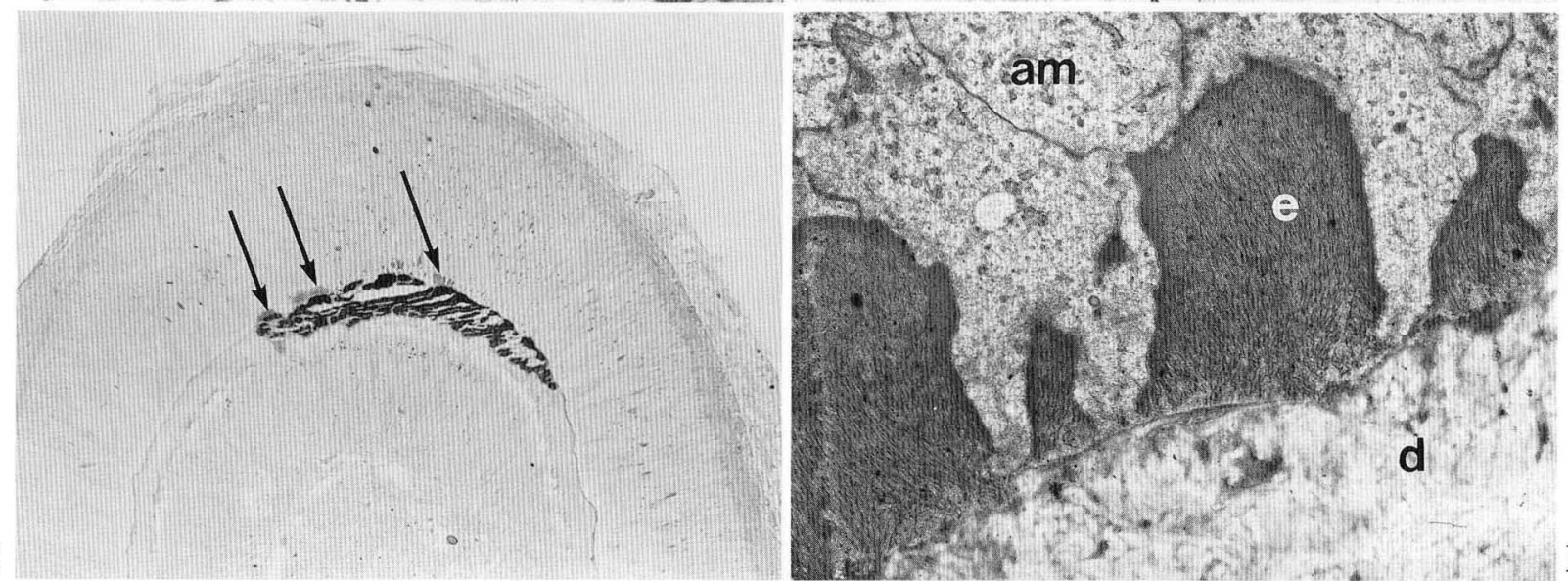

D
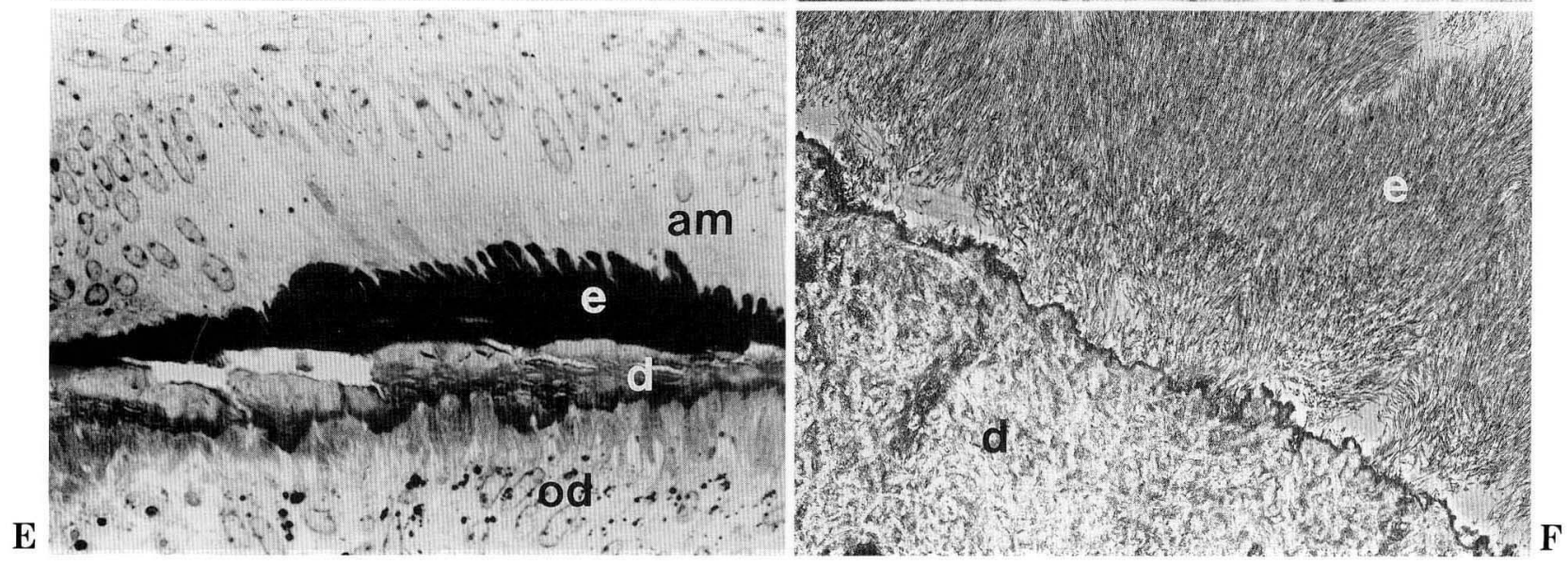

Fig. 2. A first mandibular molar (bell stage) of an 18-day-old mouse embryo cultured in a serum-free, chemically-defined medium. A. After 2 days of culture, the predentin secretion is already extensive, and each inner enamel epithelium cell is of a cylindrical shape. B. After 4 days, the calcified dentin has appeared partially at the cusp tip. Thick predentin exists and the ameloblasts have polarized. C. A section stained by the VON KossA reaction after 6 days. Enamel has been secreted insularly at the cusp tip (arrows). D. Electron micrograph of the same stage as shown in C. Needle-like crystals of enamel $(e$ ) between the Tomes' process of the ameloblasts (am) are seen, and dentin $(d)$ has also calcified. E. After 8 days, a layer of enamel is present, but a subjacent layer of dentin has either a thin layer of predentin or a direct layer of odontoblast. am Ameloblast, $e$ enamel, $d$ dentin, od odontoblast. F. An electron micrograph of the same stage as shown in $\mathbf{D}$, confirms the occurrence of enamel crystals $(e) . d$ Dentin. A-C: $\times 270, \mathrm{D}: \times 9,000, \mathrm{E}: \times 530, \mathrm{~F}: \times 6,600$ 
for morphological observation, and the resin was removed from the adjacent sections with ethanol supersaturated sodium hydroxide. The samples were processed for the VON KOSSA histochemical assay to identify the position of calcium salt precipitates within the dentin and enamel matrices. These specimens were subsequently counterstained lightly with toluidine blue.

\section{RESULTS}

The first mandibular molar of the 18-day-old mouse embryo was at the bell stage of development. The cusp pattern was evident and the odontoblasts had differentiated into cylinders, whereas the ameloblasts did not show any appreciable polarized characteristics (Fig. 1).
A
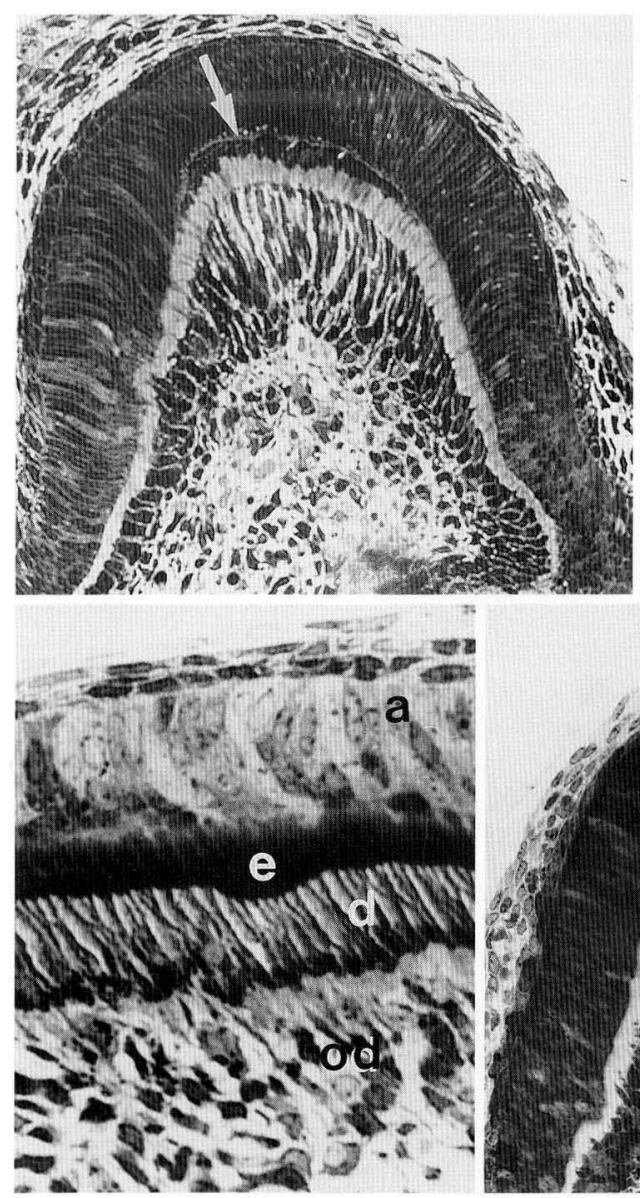

$\mathrm{C}$

D
B
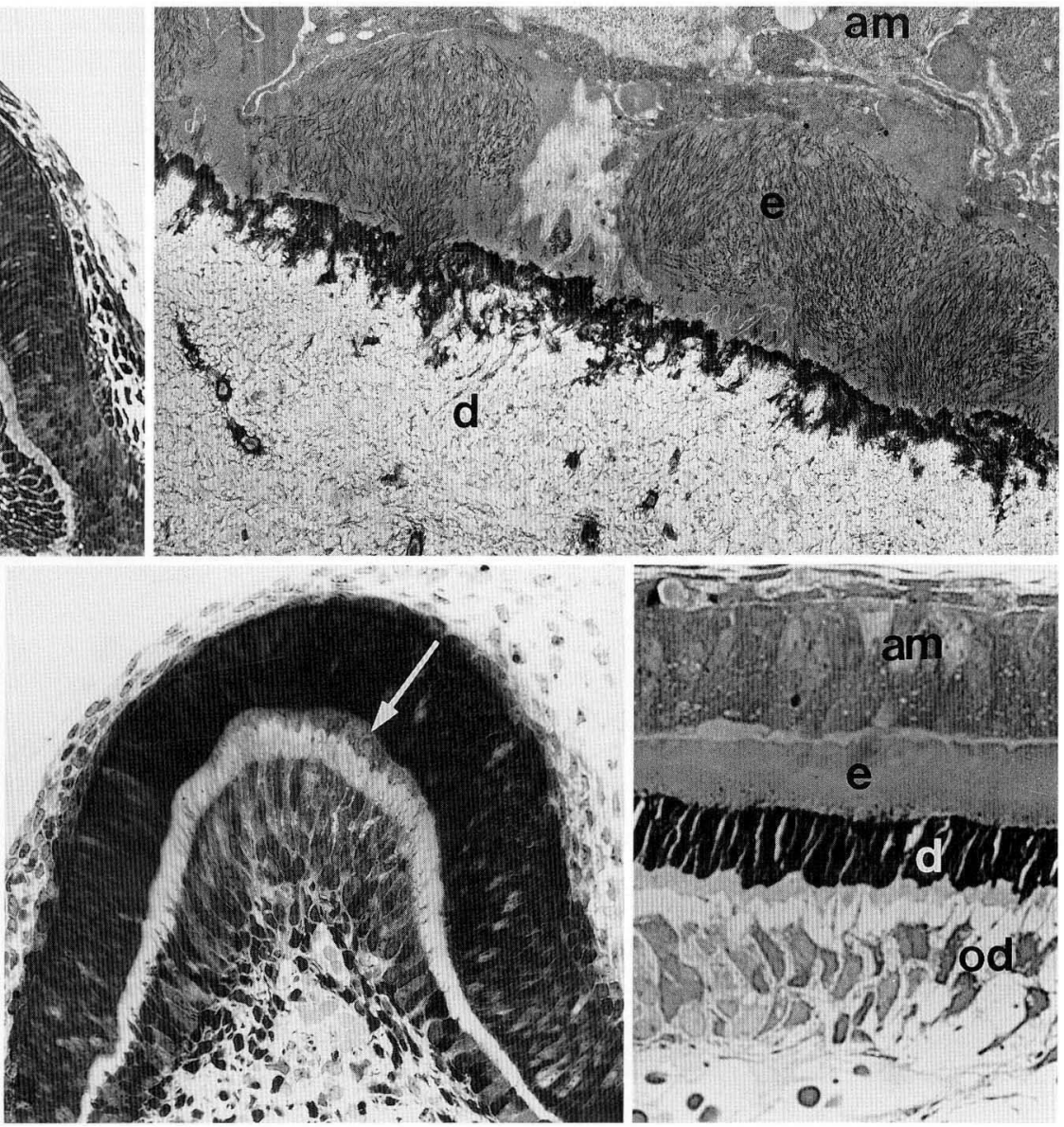

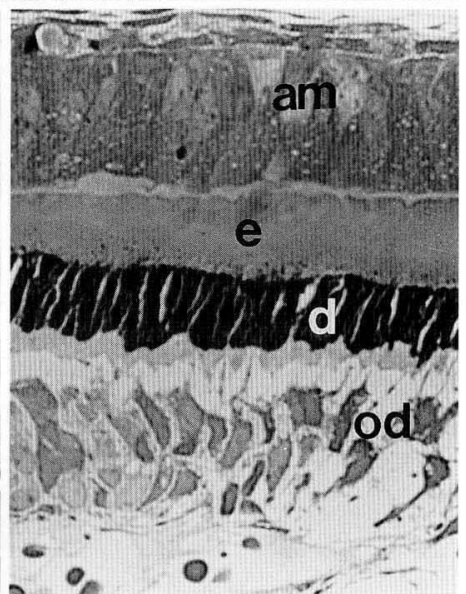

E

Fig. 3 A-C. The first mandibular molar of an 18-day-old mouse embryo cultured in a serum-free, chemicallydefined medium supplemented with $1 \mathrm{mM}$ sodium $\beta$-glycerophosphate $\left(\mathrm{Na}-\beta-\mathrm{GPO}_{4}\right)$. A. After day 4 of culture, a very thin enamel layer exists partly at the cusp tip (arrow). B. Electron micrograph shows needle-like crystals of the enamel $(e)$ over the calcified dentin $(d)$. Extracellular matrices occur between the ameloblasts $(a m)$ and enamel crystals $(e)$. C. Within 6 days in vitro, there are layers of ameloblasts $(a m)$, enamel $(e)$, dentin $(d)$ and odontoblasts $(o d)$, but no predentin. D-E. The first mandibular molar of an 18-day-old embryo molar germ cultured in a serum-free, chemically-defined medium supplemented with $5 \mathrm{mM} \mathrm{Na}-\beta$-GPO . D. The explant cultured for 2 days shows predentin and mineralized dentin existing partially at the cusp tip (arrow). E. As early as after 4 days, the extent of dentin and enamel formation is the same as in the molar germs cultured in $1 \mathrm{mM}$ $\mathrm{Na}-\beta-\mathrm{GPO}_{4}$ for 6 days. By the vON KosSA reaction, calcium salt precipitation is identified within the dentin and enamel, but the reaction in the enamel is less than that of dentin due to immature mineralization. A and D: $\times 270, \mathrm{C}$ and $\mathrm{E}: \times 530, \mathrm{~B}: \times 5,800$ 


\section{Eighteen-day-old embryonic molar cultured in serum-free medium}

After 2 days of culture, columnar odontoblasts were found to be arranged in a layer. Predentin secretion was more extensive, and the odontoblast processes sometimes passed into the predentin (Fig. 2A). Within 4 days, calcified dentin partially appeared at the cusp tip, and a thick secretion of predentin existed extensively along the cuspal form. The nuclei of the ameloblasts had polarized on the proximal side (Fig. 2B). After 6 days, a small amount of enamel had been secreted insularly on the mineralized dentin at the tip of the cusp (Fig. 2C, arrows). In the dentin area of the cusp tip, calcium precipitation was observed by the vON Kossa reaction (Fig. 2C). Electron microscopy revealed deposits of needle-like enamel crystals between the Tomes' processes (Fig. 2D).

After 8 days, mineralization of the enamel had advanced further than that of the 6 day culture. Almost all the ameloblasts had differentiated into cylindrical forms (Fig. 2E). Needle-like enamel crystals oriented in irregular directions could be identified by electron microscopy (Fig. $2 \mathrm{~F}$ ). After 8 or more days in culture, the height of the ameloblasts decreased in the region where enamel had been secreted and calcified.

A total of 101 cultured molars were consistent with these observations.

\section{Effects of sodium $\beta$-glycerophosphate on 18-day- old molar germs}

In the tooth germ of 18-day-old embryos cultured for 2 days in the serum-free, chemically-defined medium supplemented with $1 \mathrm{mM}$ sodium $\beta$-glycerophosphate $\left(\mathrm{Na}-\beta-\mathrm{GPO}_{4}\right)$, mineralization of dentin was observed at the cusp tip. After 4 days, dentin formation was extensive, with a very thin enamel layer covering part of the mineralized dentin (Fig. 3A, arrow). Electron microscopy confirmed that the enamel contained needle-like crystals (Fig. 3B). Both dentin and enamel developed extensively until the 6th day of culture. However, there was little or no predentin beneath the mineralized dentin (Fig. 3C). Moreover, after 10 days, tooth germs entered abnormal morphological development.

In 18-day-old mouse embryonic molars incubated

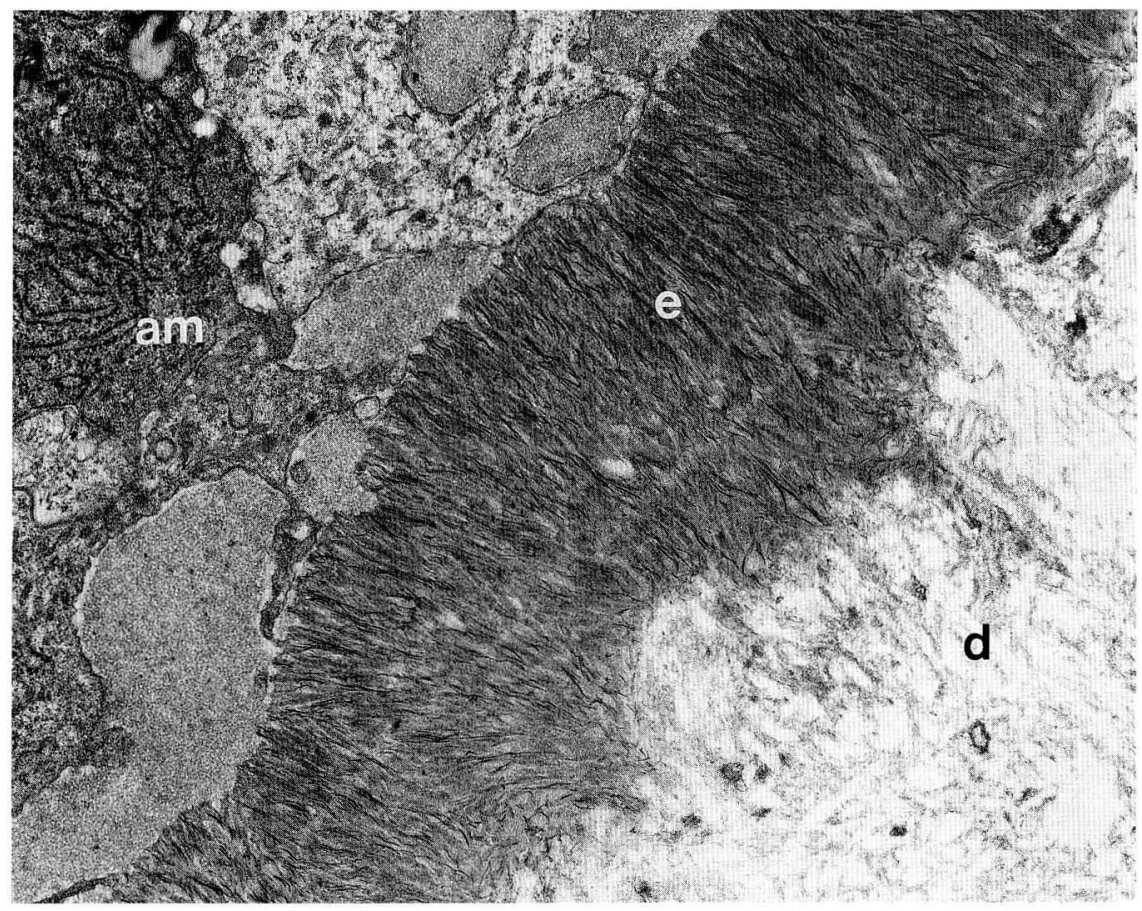

Fig. 4. Eighteen-day-old molar germ cultured in serum-free, chemically-defined medium supplemented with $10 \mathrm{mM}$ Sodium $\beta$-glycerophosphate. Dentin $(d)$ and needle-like enamel crystals (e) exist in parts of the molar. am Ameloblast, od odontoblast. $\times 16,400$ 
for 2 days in serum-free medium supplemented with 5 $\mathrm{mM} \mathrm{Na}-\beta-\mathrm{GPO}_{4}$, predentin had been secreted in a large area along the odontoblast layer, and mineralized dentin existed partially at the cusp tip (Fig. 3D, arrow). Within 4 days, the formation of dentin and enamel had developed to the same level as that of the molars cultured in a medium supplemented with 1 $\mathrm{mM} \mathrm{Na}-\beta-\mathrm{GPO}_{4}$ for 6 days. Using the voN KossA stain, the dentin was heavily stained whereas the enamel was more lightly stained (Fig. 3E). Until the 6 th day, the areas of dentin and enamel were extensively mineralized. However, there was little or no predentin beneath the mineralized dentin as seen in the $1 \mathrm{mM} \mathrm{Na}-\beta-\mathrm{GPO}_{4}$ cultures. In the case of the cultures supplemented with $10 \mathrm{mM} \mathrm{Na}-\beta-\mathrm{GPO}_{4}$, by 2 days of culture, the dentin and a small amount of enamel had already formed with the development of odontoblasts and ameloblasts (Fig. 4). The tooth germ configuration was crooked to some extent. Table 1 shows the above results obtained from 18day-old embryonic molar germs.

A total of 110 cultured molars were consistent with these observations.

In 18-day-old embryonic tooth germs, a short exposure to $\mathrm{Na}-\beta-\mathrm{GPO}_{4}$ promoted calcification of the enamel and dentin. It was, however, clear that long exposure and high doses of $\mathrm{Na}-\beta-\mathrm{GPO}_{4}$ tend to inhibit normal development.

\section{DISCUSSION}

Our results indicate that the embryonic first mandibular molar at the bell stage of mice progressed to both dentin and enamel biomineralization in a serumfree, chemically-defined medium in vitro, with maintenance of the three-dimensional structure. In addition, the duration of the culture for the biomineralization of the explants in this study was substantially shortened as compared to earlier reports: the dentin of 18-day-old embryonic molars calcified within 4 days and enamel within 6 days.

The present study provided results similar to those of BRINGAS et al. (1987), Evans et al. (1988), SLAVkin (1988) and SLAVKIN et al. (1982b, 1988) in that the dentin and enamel of the mouse tooth germs were mineralized in a serum-free, chemically-defined medium. These investigators demonstrated that the dentin and enamel extracellular matrix of the embryonic cap stage (15-16 days of gestation) molars formed and mineralized in a serum-free, chemically-defined medium for up to 3 weeks or 31 days of culture. Their systems, however, could not maintain the threedimensional structure of the molar germs, which is important for a normal expression of the intrinsic development program.

We were able to achieve mineralization of the dentin and enamel in 18-day-old tooth germs cultivated in a serum-free, chemically-defined medium by the flotation method. Currently, no such descriptions

Table 1. Mineralization summary of an 18-day-old embryonic mouse molar germ cultured in a serum-free, chemically-defined medium supplemented with sodium $\beta$-glycerophosphate $\left(\mathrm{Na}-\beta\right.$ - $\left.\mathrm{GPO}_{4}\right)$

\begin{tabular}{|c|c|c|c|c|c|}
\hline & & Serum-free & $1 \mathrm{mM} \mathrm{Na}-\beta-\mathrm{GPO}_{4}$ & $5 \mathrm{mM} \mathrm{Na}-\beta-\mathrm{GPO}_{4}$ & $10 \mathrm{mM} \mathrm{Na}-\beta-\mathrm{GPO}_{4}$ \\
\hline \multirow[t]{2}{*}{ Day 2} & Dentin & - & + & + & ++ \\
\hline & Enamel & - & - & - & + \\
\hline \multirow[t]{2}{*}{ Day 4} & Dentin & + & + & ++ & $*$ \\
\hline & Enamel & - & + & ++ & $*$ \\
\hline \multirow[t]{2}{*}{ Day 6} & Dentin & + & ++ & ++ & $*$ \\
\hline & Enamel & + & ++ & ++ & $*$ \\
\hline \multirow[t]{2}{*}{ Day 8} & Dentin & ++ & ++ & $*$ & $*$ \\
\hline & Enamel & ++ & ++ & $*$ & $*$ \\
\hline \multirow[t]{2}{*}{ Day 10} & Dentin & ++ & $*$ & $*$ & $*$ \\
\hline & Enamel & ++ & $*$ & $*$ & $*$ \\
\hline
\end{tabular}

- : Dentin or enamel has not been secreted and/or mineralized; + , slight calcification in only the cusp tip area, ++ : extensive mineralization along the cuspal form, $*$ : Abnormal contours of the tooth germ. 
of calcification are available which take place as early as reported here in a serum-free, chemicallydefined medium. Dentin of 17-day-old tooth germs had formed after 6 days of culture and enamel after 8 days (data not shown). These timings in 17-day-old embryonic molar germs were found to lag behind that of the 18-day gestation explants by about 2 days. Mineralization of molar germs in the flotation method was also recognized at shorter periods in 17-day-old tooth germs. The intrinsic cusp development, moreover, was clearly maintained in our culture system. These data indicate the usefulness of our flotation method in a serum-free, chemically-defined medium.

Bone, another mineralized tissue, has usually been cultured in media supplemented with $10 \mathrm{mM}$ sodium $\beta$-glycerophosphate $\left(\mathrm{Na}-\beta\right.$ - $\left.\mathrm{GPO}_{4}\right)$ and serum (TENENBaUm, 1981; Tenenbaum and HeErsche, 1982; BeLLOWS et al., 1986; GERSTENFELD et al., 1987). LAINE and THESLEFF (1986) stated that the mineralization of dentin in a culture medium supplemented with $5 \mathrm{mM}$ $\mathrm{Na}-\beta-\mathrm{GPO}_{4}$ and serum was rather exceptional and less healthy than the control medium. They could not achieve calcification of dentin in other cultures with different concentrations $(0.25,0.5,1.0,2.5$ and $10 \mathrm{mM})$ of $\mathrm{Na}-\beta-\mathrm{GPO}_{4}$. In contrast, it is obvious that the low concentration $(1 \mathrm{mM})$ used in this study possesses the capability for tissue specific mineralization. This suggests that some unidentified factors in the serum might be inhibitors of $\mathrm{Na}-\beta$-GPO $\mathrm{GP}_{4}$ (TENENBAUM, 1981). It is consistent with the interpretation that only a little organic phosphate affects the calcification of explants in vitro (TENENBAUM, 1981), because these serum-born inhibitors were not present in our serumfree medium.

Dentin and enamel were found in molars cultured for 6 days in a medium supplemented with $1 \mathrm{mM}$ $\mathrm{Na}-\beta-\mathrm{GPO}_{4}$ and 4 days in $5 \mathrm{mM} \mathrm{Na}-\beta-\mathrm{GPO}_{4}$. However, the layer of predentin was either slightly thick, or the dentin had direct contact with the odontoblasts due to the lack of predentin. LAINE and THESLEFF (1986) observed a similar phenomenon in 17-day-old embryonic molars cultured for 14 days in a BGJb medium supplemented with $5 \mathrm{mM} \mathrm{Na}-\beta-\mathrm{GPO}_{4}$. They suggested that there was a threshold for the onset of calcification, that exceeding this threshold may be necessary to begin the accumulation of calcium, and that mineralization continued readily after it started. According to their suggestions, the present results may be accounted for by the fact that rapid mineralization of dentin might occur when the calcium level at the microenvironment exceeds the threshold due to the addition of $\mathrm{Na}-\beta-\mathrm{GPO}_{4}$. On the other hand, when GERSTENFELD et al. (1987) cultured chicken osteoblasts in a medium supplemented with $10 \mathrm{mM}$ $\mathrm{Na}-\beta-\mathrm{GPO}_{4}$, the accumulation of calcium and phosphate as well as alkaline phosphatase activity increased over those of the control. According to LAINE and ThEsLEFF (1986) and GERSTENFELD et al. (1987), the addition of $\mathrm{Na}-\beta-\mathrm{GPO}_{4}$ accelerated calcification, but did not have any effect on collagen synthesis or protein deposition. Owing to disordered metabolic activity during dentinogenesis, molars may not be able to maintain a balance between the mineralization of dentin and secretion of predentin in a medium supplemented with $\mathrm{Na}-\beta-\mathrm{GPO}_{4}$.

In earlier studies, explants cultivated by the modified Trowell method showed an oppressed perpendicular appearance, and closely adhered to the filter paper (LEVENSON, 1976; THESLEFF, 1976; SLAVKIN et al., 1982a). This disordered morphology in molars suggests that the physiological balance or many other situations of morphogenesis and calcification differ from in vivo conditions. In contrast, it could be that, for the maintenance of the three-dimensional structure of the explants, the flotation method used in the present study results in a similar appearance to the molar germ in vivo as opposed to that using the modified Trowell method (SAKAKURA, 1986; SAKAKURA et al., 1989).

This report demonstrates that the flotation method induces molar germ differentiation and mineralization much sooner than the methods reported previously (BRINGAS et al., 1987; Evans et al., 1988; SLAVKIN, 1988; Slavkin et al., 1988). Since cell metabolic activity decreases with long term cultivation, the shorter culture affords better observation of the mineralization of dentin and enamel and more precise analysis of the relation between the in vitro and the in vivo states. This culture system will be further be useful for studying exogenous factors on tooth germs such as growth factors and hormones.

\section{REFERENCES}

Ameloot, P. C., D. Coomans, J. Smeyers-Verbeke and P. Boute: Characteristic of mineralization of rat molar tooth germs in organ culture. J. Biol. Buccale 14: 25-37 (1986).

Bellows, C. G., J. E. Aubin, J. N. M. Heersche and M. E. Antosz: Mineralized bone nodules formed in vitro from enzymatically released rat calvaria cell populations. Calcif. Tiss. Int. 38: 143-154 (1986).

Bringas, P., Jr., M. Nakamura, E. Nakamura, J. Evans and H. C. Slavkin: Ultrastructural analysis of enamel formation during in vitro development using chemically-defined medium. Scanning Microscopy 1: 1103-1108 (1987). 
Bronckers, A. L. J. J.: Effect of oxygen tension on matrix formation and mineralization in hamster molars during development in vitro. J. Biol. Buccale 11: 195207 (1983a).

- : A histological and biochemical study of the effect of vitamin C-deficiency on induction of amelogenesis in hamster molars in vitro. Arch. Oral Biol. 28: 681-692 (1983b).

Bronckers, A. L. J. J., T. J. M. Bervoets and J. H. M. WöLTGENS: Amelogenesis and mineralization in vitro. Cell Biol. Int. Rep. 5: 771 (1981).

- — : Effect of developmental stage of explants on further in-vitro development of hamster molars. Arch. Oral Biol. 28: 69-77 (1983).

Evans, J., P. Bringas, Jr., M. Nakamura, E. Nakamura, V. Santos and H. C. Slavkin: Metabolic expression of intrinsic developmental programs for dentine and enamel biomineralization in serumless, chemicallydefined, organotypic culture. Calcif. Tiss. Int. 42: 220230 (1988).

Gerstenfeld, L. C., S. D. Chipman, J. Glow aCki and J. B. Lian: Expression of differentiated function by mineralizing cultures of chicken osteoblasts. Devel. Biol. 122: 49-60 (1987).

HaY, M. F.: The development in vivo and in vitro of the lower incisor and molars of the mouse. Arch. Oral Biol. 3: 86-109 (1961).

Laine, M. and I. TheslefF: Development of mouse embryonic molars in vitro: an attempt to design defined culture conditions allowing mineralization. J. Biol. Buccale 14: 15-23 (1986).

Levenson, G. E.: Effect of ascorbic acid deficiency on mouse second molar tooth germs cultivated in vitro. J. Embryol. Exp. Morphol. 36: 73-85 (1976).

SAKakURA, Y.: A new culture method assuring the threedimensional development of the mouse embryonic molar tooth in vitro. Calcif. Tiss. Int. 39: 271-278 (1986).

Sakakura, Y., N. FuJiwara and T. Nawa: A simple, disposable, and improved organ culture system for maintaining three-dimensional development of mouse embryonic molars. In Vitro Cell. Devel. Biol. 25: 959964 (1989).

Slavkin, H. C.: Amelogenesis in vitro. J. Dent. Res. 58: 735-739 (1979).

-: Gene regulation in the development of oral tissues. J. Dent. Res. 67: 1142-1149 (1988).

Slavkin, H. C., M. Zeichner-David, M. MacDougall, P. Bringas, C. Bessem and L. S. Honig: Antibodies to murine amelogenins: Localization of enamel proteins during tooth organ development in vitro. Differentiation 23: 73-82 (1982a).

Slavkin, H. C., L. S. Honig and P. Bringas, Jr.: Experimental dissection of avian and murine tissue interactions using organ culture in a serumless medium free from exogenous (non-defined) factors. In: (ed. by) B. SARnAT and D. Dixon: Factors and mechanisms influencing bone growth. Alan R. Liss, Inc., New York, 1982b (p. 217-228).
Slavkin, H. C., P. Bringas, Jr., C. Bessem, V. Santos, M. Nakamura, M.-Y. Hsu, M. L. Snead, M. ZeichnerDAVID and A. G. Fincham: Hertwig's epithelial root sheath differentiation and initial cementum and bone formation during long-term organ culture of mouse mandibular first molars using serumless, chemicallydefined medium. J. Periodont. Res. 23: 28-40 (1988).

Salavkin, H. C., P. Bringas, Jr., Y. Sasano and M. MAYo: Early embryonic mouse mandibular morphogenesis and cytodifferentiation in serumless, chemically defined medium: a model for studies of autocrine and/ or paracrine regulatory factors. J. Craniofac. Genet. Devel. Biol. 9: 185-205 (1989).

Slavkin, H. C., Y. Sasano, S. Kikunaga, C. Bessem, P. Bringas, Jr., M. Mayo, W. Luo, G. MaK, L. RALL and M. L. SnEAd: Cartilage, bone and tooth induction during early embryonic mouse mandibular morphogenesis using serumless, chemically-defined medium. Connect. Tiss. Res. 24: 41-51 (1990).

Tenenbaum, H. C.: Role of organic phosphate in mineralization of bone in vitro. J. Dent. Res. 60: 1586-1589 (1981).

Tenenbaum, H. C. and J. N. M. Heersche: Differentiation of osteoblasts and formation of mineralized bone in vitro. Calcif. Tiss. Int. 34: 76-79 (1982).

TheslefF, I.: Differentiation of odontogenic tissues in organ culture. Scand. J. Dent. Res. 84: 353-356 (1976).

WigGleswoRTH, D. J.: Formation and mineralization of enamel and dentine by rat tooth germs in vitro. Exp. Cell Res. 49: 211-215 (1968).

Wigglesworth, D. J. and A. F. HAYward: The ultrastructure of dentinogenesis and amelogenesis in rat molar tooth germs grown as organ cultures in vitro. $Z$. Zellforsch. 138: 171-186 (1973).

Woltgens, J. H. M., D. M. LyaruU, T. J. M. Bervoets and A. L. J. J. BRonckers: Effects of calcium and phosphate on secretion of enamel matrix and its subsequent mineralization in vitro. Adv. Dent. Res. 1: 196-201 (1987).

Yamada, M., P. Bringas, Jr., M. Grodin, M. MaC. Dougall, M. Cummings, J. Grimmett, B. Weliky and H. C. Slavkin: Chemically-defined organ culture of embryonic mouse tooth organs: morphogenesis, dentinogenesis and amelogenesis. J. Biol. Buccale 8: 127-139 (1980).

Dr. Naoki FujIWARA

Department of Oral Anatomy

Iwate Medical University School of Dentistry 1-3-27 Chuo-dori, Morioka

020 Japan

藤 原 尚 樹

020 盛岡市中央通 1-3-27

岩手医科大学歯学部

口腔解剖学第二講座 